${ }^{1}$ Department of Restorative Dentistry, Piracicaba Dental School, University of Campinas (UNICAMP), Piracicaba, SP, Brazil.
Corresponding author:

Dr. Marcelo Giannini

(D) https://orcid.org/0000-0002-7260-5231 Department of Restorative Dentistry Operative Dentistry Division Piracicaba Dental School State University of Campinas Av. Limeira, 901 - Piracicaba, SP, Brazil

PO Box 52, Zip Code: 13414-903,

Phone: 55-19-2106-5338

e-mail: giannini@fop.unicamp.br

Received: June 26, 2019

Accepted: January 22, 2020

\section{Influence of desensitizers agents on the dentin bond strength after one-year water storage}

\author{
Gabriel Nima1', Renata Bacelar-Sá1, Marcelo Giannini ${ }^{1, *}$
}

Aim: Evaluate the effect of adhesives systems combined with desensitizer agents on the microtensile bond strength ( $\mu$ TBS) of a composite resin to dentin. Methods: Cervical dentin of thirty-two human molars were used to simulate hypersensitivity areas. The teeth were divided into four groups $(n=8)$, according to the type of adhesive system and desensitizer agents. No desensitizer was used in the control (Clearfil SE Bond - CS). Two experimental groups were pretreated with either MS Coat Bond (MS) or Biofluorid 12 (BF) immediately prior to bonding with CS. The last group corresponded to Gluma Comfort Bond + Desensitizer (GC) application. After dentin treatments, a composite block was built-up on dentin surface and after 24 hours teeth were serially sectioned to obtain bonded bean specimens. Beams were stored in water for 24 hours or one year. Subsequently, the specimens were submitted to the $\mu$ TBS test. Data were analyzed by two-way mixed ANOVA and Bonferroni's test $(a=0.05)$. Results: At 24 hours, there was no significant difference in $\mu$ TBS among groups. However, at one year, dentin treated with MS or BF demonstrated significantly lower $\mu$ TBS of CS to dentin compared to control and GC, which kept their $\mu$ TBS stable. Conclusion: The effect of MS and BF desensitizer agents on the $\mu \mathrm{TBS}$ of $\mathrm{CS}$ to dentin did not reduce the $\mu \mathrm{TBS}$ at 24 hours, but it decreases significantly after one year.

Keywords: Dentin desensitizing. Dentin sensitivity. Calcium Fluoride. Oxalic acid. 


\section{Introduction}

A common problem in dental practice is dentin hypersensibility, either on exposed root surfaces or under restorations. Dentin hypersensibility is characterized by pain that could be presented from mild to intense sensitivity ${ }^{1-4}$. Some conditions like periodontal disease, gingival recession, abrasion, caries, and the development of non-carious cervical lesions may result in exposed dentin ${ }^{4,5}$. Dentin hypersensitivity arises from the application of an exogenous stimulus (chemical, mechanical, evaporative or thermal) on the exposed dentin surface ${ }^{1,2,6,7}$

Several theories have been suggested to explain the mechanism of dentinal hypersensitivity. The Brännström's hydrodynamic theory, the most widely accepted, assumes that the application of stimuli to the exposed dentin surface causes movement of the dentinal fluid that stimulates the mechanical receptors, causing pain ${ }^{8}$.

Numerous methods have been proposed to treat or manage dentin hypersensitivity $^{1,4,5,9}$. These methods include the occlusion of dentinal tubules through the application of sedative agents $\mathrm{s}^{3-5,10}$, cavity varnishes, dentin bonding agents ${ }^{11}$, resin composite restorations, lasers ${ }^{12,13}$, and dentin remineralization strategies ${ }^{14,15}$. However, the most frequent treatment consists in occluding the dentinal tubule through the use of desensitizer agents ${ }^{2,9}$, which are based on fluoride, oxalate, potassium nitrate, and calcium phosphate $\mathrm{e}^{6,9,16}$.

The desensitizing agents could reduce the dentin hypersensibility using two mechanisms: by the depolarization of nerve fibers with an immediate effect and by the gradual occlusion of the tubules reducing the pain after several applications ${ }^{7}$. In recent years, desensitizers have been used in combination with adhesive systems in most adhesive restorative procedures. Although desensitizers have demonstrated that effectively reduce the sensibility, little is known about the possible adverse effects on the adhesive performance by the use of desensitizers, and the results are still controversial. Several studies have reported that the use of a desensitizer previous to the adhesive application did not reduce the dentin bond strength ${ }^{5,17}$. On the other hand, other studies have shown that the bond strength to dentin is reduced after using desensitizing agents $7,10,18$. However, most previous studies have evaluated the bond strength either immediately or in short periods of time after restoration placement ${ }^{17,18}$. Thus, the long-term effect of desensitizers on the dentin bond strength is unclear and needs to be clarified, to better understand the effects of this therapy on the longevity of composite restorations.

This study aimed to evaluate the effect of the previous application of desensitizer agents on the micro-tensile bond strength of a two-step self-etching adhesive to dentin, comparing to the same self-etching adhesive without desensitizing treatment and to a two-step, etch-and-rinse adhesive containing a desensitizer in its composition, after 24 hours and one year of water storage. The null hypotheses investigated were that 1- application of desensitizer agents would not affect the $\mu$ TBS of the self-etch adhesive, regardless the evaluation time and 2- no $\mu$ TBS reduction would be observed after one year. 


\section{Materials and Methods}

\section{Tooth Preparation}

This research was approved by the Ethics Committee of Piracicaba Dental School, University of Campinas (2.099.16). Thirty-two extracted, non-carious permanent human molars were collected and stored in aqueous solution containing thymol crystals at $4^{\circ} \mathrm{C}$. The crowns were separated from the roots with a slow-speed diamond saw in a precision low-speed cutting machine (Isomet 1000, Buehler Ltd, Lake Bluff, IL, USA). Buccal cervical surfaces were abraded with 180 grit SiC sandpaper on a polishing machine (Aropol-E, Arotec, Cotia, SP, Brazil), under water-cooling, to remove the enamel and to expose a flat cervical dentin. This cervical area was polished with 600 -grit SiC for 20 seconds.

\section{Bonding procedure}

The teeth were immersed in 0,5M ethylenediamine tetra-acetic acid (EDTA) for 5 min to remove the smear layer and smear plug, simulating the morphological characteristics of hypersensitivity areas. Afterwards, teeth were washed with distilled water for one minute and placed in an ultrasonic cleaner (USC 1400; Unique, Indaiatuba, $\mathrm{SP}$, Brazil) for three minutes. Then, the teeth were randomly divided into four groups, according to the following treatments:

- Group CS: Dentin surfaces were treated with Clearfil SE Bond. The self-etch primer was applied, left for $20 \mathrm{~s}$ and air-dried. Bonding resin was applied over priming, gently air-dried and polymerized for $10 \mathrm{~s}$.

- Group BF+CS: Biofluorid 12 was applied to dentin and after 2 min, Clearfil SE Bond the adhesive was applied over desensitizing dentin as previously described.

- Group MS+CS: MS Coat One was applied for $30 \mathrm{~s}$, followed by water rinsing and air-dried. The adhesive Clearfil SE Bond was applied over desensitizing dentin as previously described.

- Group GC: $37 \%$ phosphoric acid was applied for $10 \mathrm{~s}$ followed by water rising. Dentin surface was left visibly moist, the adhesive Gluma Comfort Bond + Desensitizer was applied, and light-cured for $10 \mathrm{~s}$.

The adhesives were polymerized using a polywave LED curing light (Bluephase G2, Ivoclar Vivadent, Schaan, Liechtenstein) using the high power mode. The composite resin (Filtek Supreme Ultra, shade A2E, 3M Oral Care, St Paul, MN, USA) block was built-up incrementally on the bonded cervical dentin surface. Each $2 \mathrm{~mm}$-increment was light cured for 20 seconds and teeth were stored in distilled water at $37^{\circ} \mathrm{C}$ for 24h. The composition of the materials (adhesives and desensitizing agents) used is presented in Table 1. 
Table 1. Description of the materials used in the study

\begin{tabular}{|c|c|c|}
\hline $\begin{array}{l}\text { Material } \\
\text { (batch number) }\end{array}$ & Manufacturer & Composition \\
\hline $\begin{array}{l}\text { Clearfil SE Bond } \\
\text { (CS) }\end{array}$ & $\begin{array}{l}\text { Kuraray Medical Inc., } \\
\text { Tokyo, Japan }\end{array}$ & $\begin{array}{c}\text { Primer: MDP, HEMA, hydrophilic dimethacrylate, } \\
\text { photo-initiator, water. } \\
\text { Bond: MDP, HEMA, Bis-GMA, hydrophobic dimethacrylate, } \\
\text { photoinitiator, silanated colloidal silica. }\end{array}$ \\
\hline $\begin{array}{l}\text { MS Coat One } \\
\text { (MS) }\end{array}$ & $\begin{array}{l}\text { Sun Medical, Shiga, } \\
\text { Japan }\end{array}$ & $\begin{array}{l}\text { 3\% MS Polymer (Copolymer of methyl methacrylate and } \\
\text { styrene sulfonic acid), } 1 \% \text { oxalic acid, water. }\end{array}$ \\
\hline $\begin{array}{l}\text { Bifluorid } 12 \\
\text { (BF) }\end{array}$ & $\begin{array}{l}\text { Voco Cuxhaven, } \\
\text { Germany }\end{array}$ & $\begin{array}{c}\text { Sodium and calcium fluoride, ethyl acetate, pyroxylin, } \\
\text { isoamylpropionate, fumed silica }\end{array}$ \\
\hline $\begin{array}{l}\text { Gluma Comfort } \\
\text { Bond +Desensitizer } \\
\text { (GC) }\end{array}$ & $\begin{array}{l}\text { Heraeus Kulzer, Hanau, } \\
\text { Germany }\end{array}$ & $\begin{array}{c}\text { 10-25\% HEMA, } 5 \% \text { glutaraldehyde, } 25-50 \% \text { ethanol, } 5-10 \% \\
\text { polyacrilic acid, } 5 \% \text { 4-META, maleic acid, } \\
\text { UDMA, photoinitiator. }\end{array}$ \\
\hline
\end{tabular}

* Abbreviations: Bis-GMA: Bisphenol A diglycidyl methacrylate; HEMA: 2-hydroxyethyl methacrylate; MDP: 10-methacryloyloxydecyl dihydrogenphosphate; UDMA: Urethane dimethacrylate; 4-META: 4-methacrylolyloxethyl trimellitate anhydride.

\section{Water storage}

After water storage for $24 \mathrm{~h}$, the restored teeth were serially sectioned with a diamond saw (Isomet 1000, Buehler Ltd, Lake Bluff, IL, USA) under water cooling, in both $X$ and $Y$ directions across the adhesive interface to obtain bonded beams with a cross-sectional area of approximately $1 \mathrm{~mm}^{2}$. The beams of each tooth were randomly divided into two groups, as follows: immediately tested ( $24 \mathrm{~h}$ ) and stored in water for one year at $37^{\circ} \mathrm{C}$ before testing (one year). Water was changed monthly.

\section{Micro-tensile bond strength evaluation ( $\mu$ TBS)}

After storage period ( $24 \mathrm{~h}$ or one year), beams were fixed by the ends to the micro-tensile device with a cyanoacrylate adhesive (Zapit, DVA, Anaheim, CA, USA) and tested in tension at a crosshead speed of $0.5 \mathrm{~mm} / \mathrm{min}$, until fractured (EZ-test, Shimadzu Co., Kyoto, Japan). The cross-sectional area of the tested was measured with a digital caliper (Mitutoyo Corp, Tokyo, Japan) after removing them from the micro-tensile device. The $\mu$ TBS of each beam was expressed in MPa.

\section{Energy-dispersive X-ray spectrometry}

After $\mu$ TBS test the dentin-side from fractured specimens were used to analyze the chemical elements present at the resin-dentin interface, using energy-dispersive X-ray spectroscopy (EDS). The fractured samples were fixed on metal stubs and sputter-coated with carbon (MED 010; Balzers Union, Balzer, Liechtenstein) prior to EDS. The X-ray detector (X-Act; Oxford, Tubney Woods, UK) was coupled to a scanning electron microscope (JSM IT 300; JEOL, Tokyo, Japan) and images were obtained for each material.

\section{Statistical analysis}

All beams were tested for each tooth, and the mean bond strength value was considered for each group ( $n=8)$. Statistical Analysis was performed with IBM SPSS 21 (SPSS Inc.; Chicago, IL, USA) software for macOS. The normality of data distribution was tested using Shapiro-Wilk test. The $\mu$ TBS data were analyzed by two-way mixed ANOVA, followed by the Bonferroni's post hoc test $(a=0.05)$. 


\section{Results}

The $\mu$ TBS means and standard deviation for experimental groups are described in Table 2. Shapiro-Wilk test indicated that the data were normally distributed $(p=0.20)$, Consequently parametric statistical analyses were applied. The two-way mixed ANOVA revealed that there are a significant effect for the "storage time" factor $(F(1,27)=8,704$; $p=0.006)$ and for the interaction Treatment $\star$ Storage time $(F(3,27)=3,304 ; p=0.035)$.

Table 2. Means and standard deviations (MPa) of $\mu$ TBS for the experimental groups at 24 hours and after one year of water storage.

\begin{tabular}{lcc}
\hline \multirow{2}{*}{ Groups } & \multicolumn{2}{c}{ Storage Time } \\
\cline { 2 - 3 } Clearfil SE Bond & 24 horas & 1 Year \\
\hline MS Coat One + Clearfil SE Bond & $33.0 \pm 9.7 \mathrm{Aa}$ & $32.1 \pm 11.8 \mathrm{Aa}$ \\
\hline Bifluorid 12+ Clearfil SE Bond & $33.4 \pm 9.0 \mathrm{Aa}$ & $20.4 \pm 7.4 \mathrm{Bb}$ \\
\hline Gluma Comfort Bond +Desensitizer & $36.1 \pm 9.0 \mathrm{Aa}$ & $20.9 \pm 8.8 \mathrm{Bb}$ \\
\hline
\end{tabular}

Upper case letters compare storage times within the same group, while lower case letters compare groups within the same storage time.

At 24 hours no difference among groups was found. However, at one year, BF+CS $(20.9 \pm 8.8 \mathrm{MPa})$ and $\mathrm{MS}+\mathrm{CS}(20.4 \pm 7.4 \mathrm{MPa})$ showed lower $\mu$ TBS than those obtained by $C S$ and $G C$, because of the $\mu$ TBS reduction after water storage for one year. The $\mu$ TBS of CS and GC kept stable following the long-term water storage.

The EDS analysis identified the presence of calcium, phosphorus, and silicon for all groups.(Fig.1) For the group BF+CS, sodium, and fluorine were detected. (Fig. 1B)

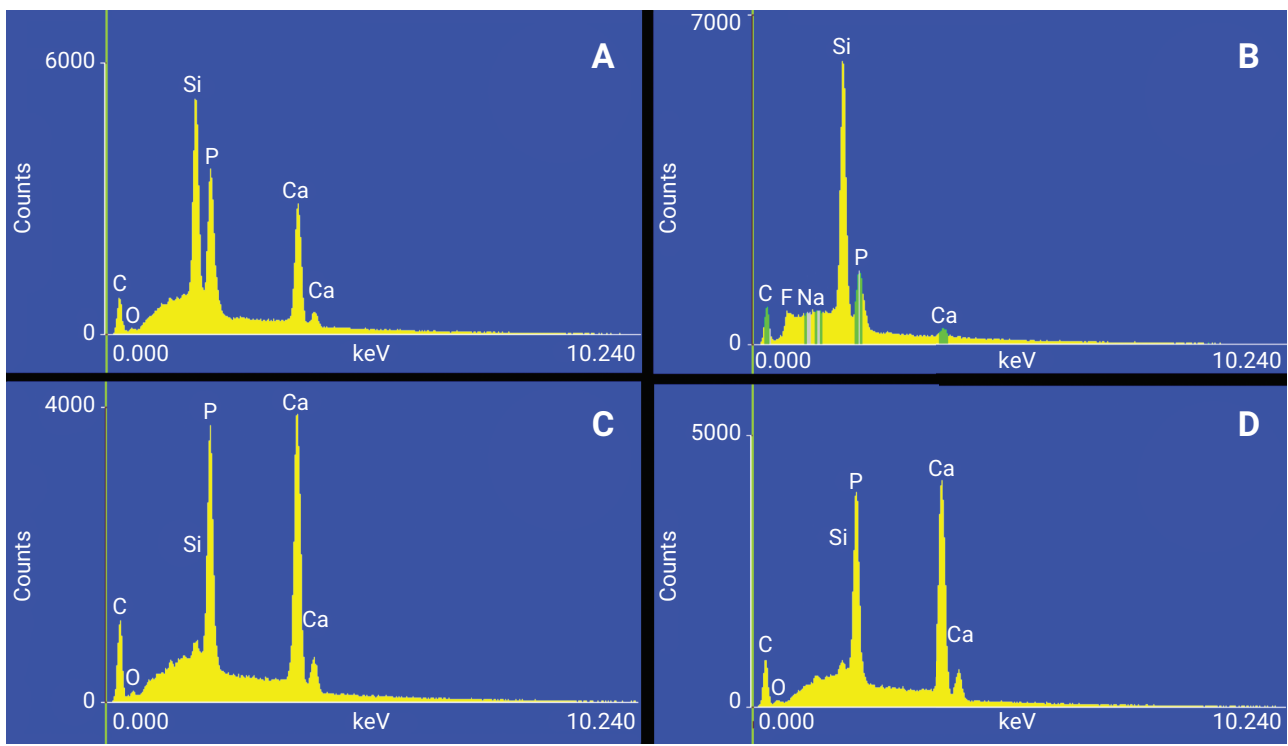

Figure 1. Identified elements by EDS analyses (A) Clearfil SE Bond, (B) Biofluorid 12 + Clearfil SE Bond, (C) MS Coat One + Clearfil SE Bond, and (D) Gluma Confort Bond + Desensitizer. 


\section{Discussion}

This study demonstrated that the previous treatment of dentin with desensitizer agents did not compromise the early dentin $\mu$ TBS of self-etch adhesive. However, a significant reduction in $\mu$ TBS after one-year water storage was noted when the dentin was treated with Bifluorid 12 or MS Coat One followed by the application of Clearfil SE Bond. Thus, both null hypotheses were rejected because the using of desensitizer agents (Bifluorid 12 and MS Coat One) affected the $\mu$ TBS of self-etching adhesive to dentin at one year, which were lower than CSEB and GCBD groups.

The $\mu$ TBS reduction after one year might have been the result of incompatibility between the desensitizer agents and the self-etch adhesive system or remnant of them on the dentin surface that impaired the bonding. Clearfil SE Bond is able to form a thin hybrid layer as well as to react chemically with calcium from hydroxyapatite and both bonding mechanisms might be compromised, thus the use of desensitizer agents must be avoided when using this self-etch adhesive ${ }^{19,20}$. On the other hand, the $\mu$ TBS of Gluma Comfort Bond + Desensitizer kept stable after one year.

The desensitizer agents used in this study present different compositions and are able to occlude dentinal tubules by different mechanisms of actions. MS Coat One is a single-bottle tubule sealant, based on oxalic acid and a moisture of polymethyl methacrylate and a copolymer of polystyrene sulfonic acid (Table 1) ${ }^{15}$. When the acid oxalic is applied on the dentin surface, it liberates calcium ions from the dissolution of hydroxyapatite to form calcium oxalate crystals and polymer-Ca complex 6,7,15,21,22. The efficacy of oxalate desensitizer in permeability reduction has been demonstrated ${ }^{16,18,22}$. However, previous studies have shown that the desensitizing effect promotes by the oxalic acid may not be permanent. The permeability of the tubules can be re-established by partial crystal dissolution in oral fluids or because the removal it by toothbrushing ${ }^{1,18,22}$. The use of this desensitizer agent did not influence the $\mu$ TBS of Clearfil SE Bond to dentin at 24 hours, but it was reduced after one year probably because the crystal solubilization from the dentinal fluids and storage water, which also affected the bonding and decreased the $\mu \mathrm{TBS}^{18,23}$.

Bifluorid 12 is a fluoride varnish based on sodium and calcium fluoride (Table1). The EDS analysis detected fluorine and sodium that confirm the interaction of these components with dentin surface (Fig. 1B). These compounds work in two different ways: (1) occluding the dentinal tubules by the crystallization of sodium fluoride and (2) formation of a calcium fluoride precipitation on the dentin surface ${ }^{1,6,17}$. It has been demonstrated that precipitation of calcium fluoride is slowly solubilized in saliva, which may explain the transitory action of this barrier ${ }^{1}$. Other studies have shown the loss of adhesion between dentin and the varnish in short periods of time by dissolution or for fluoride release ${ }^{11}$. According to our results, the application of Bifluorid 12 also compromised the $\mu$ TBS after one-year storage. This $\mu$ TBS reduction may be attributed to the same reasons as the MS Coat One. Gluma Comfort Bond + Desensitizer is a commercial product that combines an adhesive system and a desensitizer agent. It is an alcoholic solution that contains three resin monomers (HEMA, UDMA, and 4-META), two organic acids (polyacrylic and maleic) and 5\% glutaraldehyde as desensitizer agent ${ }^{24}$. In dentistry, besides desensitizer agent, glutaraldehyde has been 
used in many different ways such as antibacterial, cross-linker agent, and MMPs inhibitor in order to increase the resistance of collagen fibrils against enzymatic degradation ${ }^{24-26}$. Its ability as MMPs inhibitor and cross-linker agent may have played an important role to maintain the stability of the dentin $\mu$ TBS after one year ${ }^{27,28}$.

Desensitizing mechanism of Gluma Comfort Bond + Desensitizer occurs by means of two reactions ${ }^{1}$, the glutaraldehyde reacts with some proteins of the dentin fluid forming precipitates, and ${ }^{2}$ the HEMA aggregates these precipitated proteins that occludes the dentinal tubules ${ }^{29,30}$. However, little is known about the stability and durability of these precipitates that are occluding the dentinal tubules. Some studies have shown that saliva and dentinal fluid contain esterases that could degrade ester and peptide bonds of this precipitates ${ }^{17,31}$. If the dentinal fluid attacked the precipitates created by Gluma, the desensitizing activity and the bond strength should be affected. However, in this in vitro study, the bonding procedures were performed in the absence of pulpal pressure with minimum dentinal fluid. Thus, it did not influence the bond strength values, especially in the one-year storage group. Obtained data also suggested that the hybridization mechanism, the chemical interaction of the adhesive system that was promoted by 4-META and the desensitizer are the key factor to guarantee the durability of the adhesion.

The results of the EDS analysis detected calcium and phosphorus, which are chemical elements from hydroxyapatite. Regarding silicon, this chemical element is present in the composition of Bonding Resin from CS. However, for GC adhesive the presence of silicon might be from composite resin, representing remnant of composite over adhesive, such as a cohesive failure within the composite.

Therefore, despite Bifluorid 12 and MS Coat One desensitizers not having affected the initial $\mu$ TBS of Clearfil SE Bond to dentin, their application reduced the bond strength over time. Clearfil SE Bond used alone and Gluma Comfort Bond + Desensitizer adhesives promoted stable $\mu$ TBS to dentin after one year and besides their desensitizing mechanism, they could provide long-lasting restorations.

In conclusion, the effect of desensitizer agents based on fluoride varnish and oxalic acid on the $\mu$ TBS to dentin appears to be affected over time. A careful selection of the desensitizing agent must be performed.

\section{Acknowledgments}

This work was supported by the Coordination for the Improvement of Higher Educational Personnel (CAPES), Brazil [grant number 0878/2018] and the National Council for Scientific and Technological Development (CNPq), Brazil [304692/2018-2]

\section{References:}

1. Porto ICCM, Andrade AKM, Montes MAJR. Diagnosis and treatment of dentinal hypersensitivity. J Oral Sci. 2009 Sep;51(3):323-32.

2. Erdemir U, Saygi G, Yucel T, Yildiz E. Dentin hypersensitivity and recent developments in treatment options : a mini review. JSM Dent. 2016;4(4):1072. 6p. 
3. West N, Seong J, Davies M. Dentine hypersensitivity. Monogr Oral Sci. 2014;25:108-22. doi: $10.1159 / 000360749$.

4. Davari A, Ataei E, Assarzadeh H. Dentin hypersensitivity: etiology, diagnosis and treatment; a literature review. J Dent (Shiraz). 2013 Sep;14(3):136-45.

5. Zorba YO, Erdemir A, Ercan E, Eldeniz AU, Kalaycioglu B, Ulker M. The effects of three different desensitizing agents on the shear bond strength of composite resin bonding agents. J Mech Behav Biomed Mater. 2010 Jul;3(5):399-404. doi: 10.1016/j.jmbbm.2010.03.003.

6. Arısu H, Dalkıhç E, Üçtaşlı M. Effect of Desensitizing Agents on the Microtensile Bond Strength of a Two-step Self-etch Adhesive to Dentin Oper Dent. 2011 Mar-Apr;36(2):153-61. doi: 10.2341/09-381-L.

7. Cortiano FM, Rached RN, Mazur RF, Vieira S, Freire A, de Souza EM. Effect of desensitizing agents on the microtensile bond strength of two-step etch-and-rinse adhesives to dentin. Eur J Oral Sci. 2016 Jun;124(3):309-15. doi: 10.1111/eos.12263.

8. Brännström M. Sensitivity of dentine. Oral Surg Oral Med Oral Pathol. 1966 Apr;21(4):517-26. doi: 10.1016/0030-4220(66)90411-7.

9. Schmidlin PR, Sahrmann P. Current management of dentin hypersensitivity. Clin Oral Investig. 2013 Mar;17 Suppl 1:S55-9. doi: 10.1007/s00784-012-0912-0.

10. Saraç D, Külünk S, Saraç YS, Karakas Ö. Effect of fluoride-containing desensitizing agents on the bond strength of resin-based cements to dentin. J Appl Oral Sci. 2009 Sep-Oct;17(5):495-500.

11. Yu X, Liang B, Jin X, Fu B, Hannig M. Comparative in vivo study on the desensitizing efficacy of dentin desensitizers and one-bottle self-etching adhesives. Oper Dent. 2010 May-Jun;35(3):279-86. doi: 10.2341/09-346-C.

12. Omae M, Inoue M, Itota T, Finger WJ, Inoue M, Tanaka $K$, et al. Effect of a desensitizing agent containing glutaraldehyde and HEMA on bond strength to Er:YAG laser-irradiated dentine. J Dent. 2007 May;35(5):398-402

13. Kurt S, Kırtıloğlu T, Yılmaz NA, Ertaş E, Oruçoğlu H. Evaluation of the effects of Er:YAG laser, Nd:YAG laser, and two different desensitizers on dentin permeability: in vitro study. Lasers Med Sci. 2018 Dec;33(9):1883-90. doi: 10.1007/s10103-018-2546-1

14. Yang $H$, Chen Z, Yan $H$, Huang C. Effects of calcium-containing desensitizers on the bonding stability of an etch-and-rinse adhesive against long-term water storage and pH cycling. Dent Mater J. 2018 Jan 30;37(1):122-9. doi: 10.4012/dmj.2017-006.

15. Oshima M, Hamba H, Sadr A, Nikaido T, Tagami J. Effect of polymer-based desensitizer with sodium fluoride on prevention of root dentin demineralization. Am J Dent. 2015 Jun;28(3):123-7.

16. Galvão A da M, Zeola LF, Moura GF, Teixeira DNR, Gonzaga RC de Q, da Silva GR, et al. A long-term evaluation of experimental potassium oxalate concentrations on dentin hypersensitivity reduction: A triple-blind randomized clinical trial. J Dent. 2019 Oct;89:103180. doi: 10.1016/j.jdent.2019.103180.

17. Sabatini C, Wu Z. Effect of Desensitizing Agents on the Bond Strength of Mild and Strong Self-etching Adhesives. Oper Dent. 2015 Sep-Oct;40(5):548-57. doi: 10.2341/14-190-L.

18. Vachiramon V, Vargas MA, Pashley DH, Tay FR, Geraldeli S, Qian F, et al. effects of oxalate on dentin bond after 3-month simulated pulpal pressure. J Dent. 2008 Mar;36(3):178-85. doi: 10.1016/j.jdent.2007.11.011.

19. Yoshida Y, Nagakane K, Fukuda R, Nakayama Y, Okazaki M, Shintani H, et al. Comparative study on adhesive performance of functional monomers. J Dent Res. 2004 Jun;83(6):454-8.

20. Vermelho PM, Reis AF, Ambrosano GMB, Giannini M. Adhesion of multimode adhesives to enamel and dentin after one year of water storage. Clin Oral Investig. 2017 Jun;21(5):1707-1715. doi: 10.1007/s00784-016-1966-1. 
21. Zhang Y, Agee K, Pashley DH, Pashley EL. The effects of Pain-FreeR desensitizer on dentine permeability and tubule occlusion overtime, in vitro. J Clin Periodontol. 1998 Nov;25(11 Pt 1):884-91. doi: 10.1111/j.1600-051X.1998.tb02386.x

22. Tay FR, Pashley DH, Mak YF, Carvalho RM, Lai SCN, Suh BI. Integrating oxalate desensitizers with total-etch two-step adhesive. J Dent Res. 2003 Sep;82(9):703-7.

23. de Andrade e Silva SM, Malcarne-Zanon J, Carvalho RM, Alves MC, De Goes MF, Anido-Anido A, et al. Effect of Oxalate Desensitizer on the Durability of Resin-Bonded Interfaces. Oper Dent. 2010 Nov-Dec;35(6):610-7. doi: 10.2341/09-202-L.

24. Scheffel DLS, Soares DG, Basso FG, de Souza Costa CA, Pashley D, Hebling J. Transdentinal cytotoxicity of glutaraldehyde on odontoblast-like cells. J Dent. 2015 Aug;43(8):997-1006. doi: 10.1016/j.jdent.2015.05.004.

25. Lee J, Sabatini C. Glutaraldehyde collagen cross-linking stabilizes resin-dentin interfaces and reduces bond degradation. Eur J Oral Sci. 2017 Feb;125(1):63-71. doi: 10.1111/eos.12317.

26. André CB, Gomes BPFA, Duque TM, Stipp RN, Chan DCN, Ambrosano GMB, et al. Dentine bond strength and antimicrobial activity evaluation of adhesive systems. J Dent. 2015 Apr;43(4):466-75. doi: 10.1016/j.jdent.2015.01.004.

27. Reinhardt JW, Stephens NH, Fortin D. Effect of Gluma desensitization on dentin bond strength. Am J Dent. 1995 Aug;8(4):170-2.

28. Seseogullari-Dirihan R, Apollonio F, Mazzoni A, Tjaderhane L, Pashley D, Breschi L, et al. Use of crosslinkers to inactivate dentin MMPs. Dent Mater. 2016 Mar;32(3):423-32. doi: 10.1016/j.dental.2015.12.012.

29. Qin C, Xu J, Zhang Y. Spectroscopic investigation of the function of aqueous 2-hydroxyethylmethacrylate/glutaraldehyde solution as a dentin desensitizer. Eur J Oral Sci. 2006 Aug;114(4):354-9.

30. Arrais CAG, Chan DCN, Giannini M. Effects of desensitizing agents on dentinal tubule occlusion. J Appl Oral Sci. 2004 Jun;12(2):144-8.

31. Cai K, Delaviz Y, Banh M, Guo Y, Santerre JP. Biodegradation of composite resin with ester linkages: identifying human salivary enzyme activity with a potential role in the esterolytic process. Dent Mater. 2014 Aug;30(8):848-60. doi: 10.1016/j.dental.2014.05.031. 